\title{
A Happy Life Is a Journey: My Motorcycle and Me
}

\author{
P.S. kruger \\ Stefan.kruger@nwu.ac.za
}

\begin{abstract}
The motorcycle industry is showing slow growth due to the economic downturn in South Africa. However many motorcyclists use their motorcycles as a leisurely pursuit, such as attending the annual Harley Davidson Toy Run in donating back to the community in the form of charity. Marketers to attract or retain consumers on the other hand could use psychological happiness in marketing campaigns. It is said that a happy consumer is a satisfied consumer. A convenience sampling (non-probability) technique were used during the administration of the questionnaires to potential motorcycle owners $(N=357)$ attending the Harley Davidson toy run, based on their availability and willingness to participate in this research. The Structural Equation model indicated that a linear statistical significant relationship exists between personal values, self-image, personal well-being, leisure life and overall psychological happiness amongst these specialised consumers. The findings and results will be directed towards marketers of motorcyclists as well as motorcycle dealers. Finally, suggestions for further research are made.
\end{abstract}

